\title{
The Effect of Boston Brace on Muscle Length of Pa- tients with Idiopathic Scoliosis
}

\author{
Atefe Jafari Sarveolia ${ }^{1}$, Mohammadtaghi Karimi ${ }^{1}$, Keyvan Sharifmoradi ${ }^{*}$, Azade Nadi ${ }^{1}$, Parastoo Saljoughian ${ }^{1}$ \\ 1. Department of Orthotics and Prosthetics, Musculoskeletal Research Center, Isfahan University of Medical Sciences, Isfahan, Iran. \\ 2. Department of Physical Education and Sport Sciences, Faculty of Humanities, University of Kashan, Kahshan, Iran.
}

Citation: Jafari Sarveolia A, Karimi MT, Sharifmoradi K, Nadi A, Saljoughian P. The Effect of Boston Brace on Muscle Length of Patients with Idiopathic Scoliosis. Physical Treatments. 2015; 5(3):163-170.

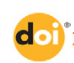

Article info:

Received: 10 Mar. 2015

Accepted: 23 Jul. 2015
Keywords:

Idiopathic scoliosis, Muscles length, Boston Brace

\begin{abstract}
A B S T RA C T
Purpose: This study aimed to assess the effect of Boston brace on trunk muscles length as well as lower limbs and trunk range of motion in patients with idiopathic scoliosis.

Methods: Five patients with idiopathic scoliosis with $\mathrm{C}$ shape curve and mean (SD) age, height, and weight of respectively $12.61(1.16)$ years, $1.53(0.08) \mathrm{m}$, and 35.6(6.1) $\mathrm{kg}$ participated in this study. Spatiotemporal parameters, range of motion of lower limbs and trunk, and muscle fiber length of erector spinae, internal and external oblique are the variables of this study. Qualysis motion analysis system and Kistler force plate was used to obtain and record raw data. Also, we used QTM and OpenSIM software to extract data. Statistics analysis was done by SPSS ver. 22 at the significance of 0.05 .
\end{abstract}

Results: Based on the results, trunk range of motion in sagittal plane decreased significantly $(\mathrm{P}=0.02)$, while pelvis range of motion in frontal plane increased significantly $(\mathrm{P}=0.006)$ during walking with brace. The changes in erector spinae and external oblique muscle fibers length were small and not significant $(\mathrm{P}>0.05)$.

Conclusion: Walking with brace decreases trunk range of motion in sagittal plane that can lead to change in erector spinae and external oblique muscles length. Thus, it is recommended that flexibility and rehabilitation of these muscles be considered. More studies are needed to assess these muscles weakness after a long time use of the brace.

\section{Introduction}

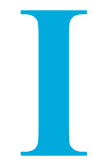

diopathic scoliosis is a lateral spinal and body deformity $[1,2]$, which is seen in previously used-to-be healthy people with no reason. Various factors such as central nerves system disorders, asymmetry in the muscles around the spine, genetics, and endocrine system problems are listed as the reasons for scoliosis.

There are several treatments for scoliosis such as physiotherapy, brace therapy, occupational therapy, casting therapy, stretching the muscles, and surgical procedures [4-8]. Using brace in scoliosis treatment is common and the main objective of brace therapy is to reduce and

* Corresponding Author:

Keyvan Sharifmoradi, $P h D$

Address: Department of Physical Education and Sport Sciences, Faculty of Humanities, University of Kashan, Kahshan, Iran

Phone: +98 (913) 8160103

E-mail: ksharifmoradi@gmail.com 
control the progression of the sine curvature [4, 9-11]. However, studies on the effects of brace on the length of the muscle fibers in these patients are scarce and inconclusive as whether using brace is capable of maintaining the changes in both sides of curvature (its convexity and concavity).

Studies conducted in patients with scoliosis using brace while walking mostly examined kinematic and kinetic variables. Wong et al. in their analysis on the effects of orthotics on lower limbs, hip, and shoulder found out that orthotics could cause a stiff gait pattern in walking and consequently the movement range limitation in shoulders, body, pelvis, and hip joint. Mahaudens et al. in a lengthy investigation on the effects of orthotics concluded that long-term use of orthotics increased the hip movement and pelvis in frontal plane, though the shoulder movement decreased. There are theories about muscle imbalance as the cause of scoliosis, but none has been proved yet $[14,15]$. Two active and passive theories discuss the effects of brace in curvature correction [16].

In the passive theory, the force from the brace blocks the curve progression, which is in contrast to the active theory of muscle contraction with the use of orthotics [16]. The study on patients with scoliosis so far focused mostly on the electrical activities of the muscles [14, 15] and quantitative studies on the changes in the length of the muscle fibers in these patients has been done by using simulating software. To our knowledge, these studies are limited into 2 "case studies". In one study, a patient's hip and lower back muscle fiber, with lateral S-shape curvature between the right and left leg [17] and in another study the length of the muscle fiber in 2 situations without wearing brace and during walking were analyzed [18]. The study results had shown no significant differences in the length of the body and the lower back muscle fibers in the convexity and concavity side [17]. In another study, putting on braces had shown no significant differences in the length of the body muscle fibers and hip during walking [18].

Knowing the changes in the length of the body muscles when using brace is of significant importance. By using the mentioned information, the rehabilitation specialists can treat and rehabilitate the patients with scoliosis with a new approach. Therefore, because of few quantitative studies on muscle fibers of the patients with scoliosis (2 case studies) $[17,18]$ and the importance of this issue in the treatment and rehabilitation of scoliosis, the present study aimed to investigate the effects of Boston brace on the length of the body muscles in these patients.

\section{Materials and Methods}

The present study has a pretest-posttest single group design in which 5 patients with scoliosis, living in Isfahan City, participated. The anthropometric characteristics of the subjects are presented in Table 1. This study was done in the first half of 2015 after obtaining the ethical approval from the Research Ethics Committee of Isfahan University of Medical Sciences, Musculoskeletal Research Center, School of Rehabilitation, and Isfahan Medical Science University. Because of the large variety of scoliosis and the research focus on the C-shaped curvature scoliosis, necessity of recruiting patients used Boston Brace for at least 6 consecutive months and taking their consent to participate in the research, it was actually impossible to enroll more patients in this study. In addition, the sample size was calculated in Minitab software with the power of 0.8 . Before running the test, all subjects' parents were asked to sign the consent forms. The subjects were introduced by the specialists from the scoliosis special clinic. All the stages of the examination and determining the angels and the scoliosis peak curve were done by the spinal surgeons. The inclusion criteria of the subjects in the study were as follows:

- Having curvature of 30 to 45 degrees,

- A curve in the region of T4 to L5,

- C-shaped curvature of the spine,

- Ability to stand and walk independently,

- Absence of operations in the lower back and lower extremities,

- Background of using brace for 6 months, and

- Absence of any other musculoskeletal problems affecting walking and standing.

Subjects with a history of other diseases were excluded from the research. All subjects had used Boston Brace. This is a short thoracolumbosacral brace that has posterior valve made of polypropylene. The area involved in brace was designed and made in the front from xiphoid to pubis and in the back and sides proportional to the patient's curvature pattern. All subjects had not used any braces other than the Boston Brace and wore it for at least 6 months.

\section{Instruments}

We used qualysis motion analysis system (made by Qualysis Company, Switzerland) with 7 cameras for 

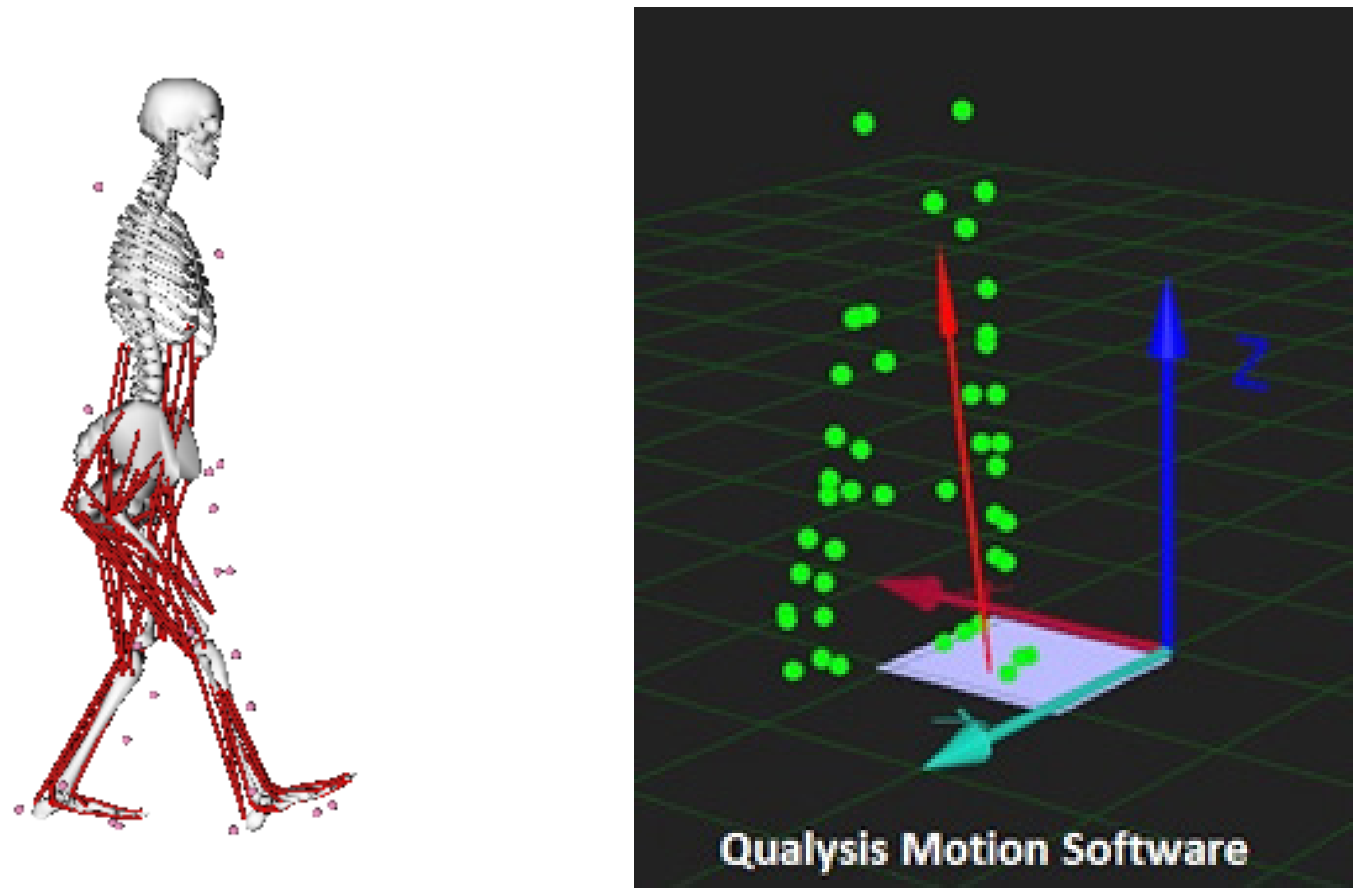

PHYSICAL TREA TMENTS

Figure 1. The place of the markers in the QTM software (Right) and musculoskeletal model in the OpenSim software (Left).

measuring gait kinematic variables. Also, center of pressure Kistler force plate $(600 \times 500 \mathrm{~mm}$, model SA 9260) (manufactured by Kistler, Switzerland) was used to record ground reaction force. The force plate was installed at the center of the pitch trajectory. The cameras were on both sides of the trajectory at a distance of $4 \mathrm{~km}$ from the center of power. Stepping path length was $10 \mathrm{~m}$ and a calibration space path was defined so that the force plate was at the center of this cubic space. Subject's distance from the walking point to the force plate was $5 \mathrm{~m}$. Figure 1 shows the attachments of 22 body markers, which reflect the infrared light with a diameter of $14 \mathrm{~mm}$. These markers are on the surface of anterior superior iliac spine, the posterior superior iliac spine, interior and posterior epicondyle on both right and left sides, heels, the first and fifth metatarsal heads and acromioclavicular joint on right and left sides, sternum, head and seventh cervical vertebrae. Also, 4 clusters, including 4 markers (Figure 1) are connected to the thighs and legs (right and left).

The protocol on the body alignment markers was based on the protocol approved by the University of Strathclyde, Glasgow, England. Data collection frequency was $120 \mathrm{~Hz}$. The data were filtered by a low pass filter with a frequency of $10 \mathrm{~Hz}$. To record the kinematic data, Qualysis Track Manager (QTM) software (version 7.5, the Qualysis Company Production, Switzerland) was used. Also, Visual 3D application (version 4, C-motion Company, USA) was used to model the patient's muscu- loskeletal system. The output of the Visual 3D was fed to OpenSim software (version 3, Stanford University, USA) to check the length of the muscle fiber in the body. Figure 1 shows the different stages to extract data from OpenSim. This application is a simulator and analyzer of the musculoskeletal system that allows the movement analysis. By simulating the musculoskeletal system, the diagnosis and treatment of pathological and abnormal movements are possible. It is also possible to investigate the biomechanical effects on the musculoskeletal system by this application [20]. After calibrating the cameras and force plate, the anthropometric data were initially recorded. Then, the subjects walked in the direction of the stepping way and the markers images and force plate data during walking were recorded. The test was conducted with and without brace. Every subject was tested 5 successful times with brace and 5 successful times without brace. Qualysis software was used to record the standing and swinging phases during walking.

\section{Research variables}

Spatiotemporal gait variables (cadence, stride length, and walking speed), the range of the lower extremities and body trunk in 3 plates, and the muscle fiber length of the spinae erector muscles as well as internal and external oblique were examined in this study. To standardize the data for the next scale, the muscle length changes were normalized to the same resting muscle. Normal 
distribution of the data was analyzed by Shapiro-Wilk test in SPSS. After confirming the normal distribution of the data, we used correlated t-test to analyze the data in SPSS version 22, at the significant level of $\mathrm{P}<0.05$.

\section{Results}

Table 2 compares the spatiotemporal parameters of gait that shows cadence, gait speed, and step length as $106.7 \pm 8.07$ step per minute, $1.12 \pm 0.12$ meter per seconds, and $1.26 \pm 0.02$ meter, respectively during walking without brace that had no significant difference with the same variables during walking with brace $(\mathrm{P}>0.05)$.

The means and the standard deviations range of lower limb movement and trunk are presented in Table 3. The range of the motion in trunk (body) in sagittal plane during walking without brace was found $8.41 \pm 0.90$ degrees that 3.20 degrees was more than walking with brace $(\mathrm{P}=0.02)$. The horizontal $(\mathrm{P}=0.42)$ and the frontal planes $(\mathrm{P}=0.10)$ of trunk motion range, also had shown no significant difference during walking with and without brace in patients with scoliosis. Although the sagittal plane motion $(\mathrm{P}=0.23)$ and the pelvis horizontal $(\mathrm{P}=0.80)$ plane had no significance difference during walking with brace and without brace, the pelvis frontal plane motion range during walking with brace was significantly more than walking without brace $(\mathrm{P}<0.00)$. Ankle muscle motion range $(\mathrm{P}=0.37)$, knee $(\mathrm{P}=0.39)$ (sagittal plane), and the hip muscle were analyzed in sagittal $(\mathrm{P}=0.31)$, frontal $(\mathrm{P}=0.97)$, and horizontal $(\mathrm{P}=0.35)$ planes and no significant difference was seen during walking with and without brace.

Muscle fiber length was another variable measured in this study. Erector spinae and the internal and external oblique muscle fiber length on the right and left sides were measured (Table 4). As it is seen, the length of muscle fibers in the erector spinae on the right $(\mathrm{P}=0.57)$, left $(\mathrm{P}=0.82)$, and external oblique on the left $(\mathrm{P}=0.007)$ decreased during walking with brace. However, the changes in the length of the internal oblique muscles on the right $(\mathrm{P}=0.057)$ and the left $(\mathrm{P}=0.83)$ and the external oblique on the right $(\mathrm{P}=0.36)$ were similar during walking with and without brace $(\mathrm{P}>0.05)$.

\section{Discussion}

The present study aimed at investigating the effects of Boston Brace on the muscle fiber length of the trunk muscles in the patients with idiopathic scoliosis during walking. The results showed that the length of the muscle fibers slightly decreased in erector spine and external oblique. Therefore, Boston brace reduces the length of the fibers in some muscles. To the authors' knowledge, there are very few studies on the changes in the length of the muscles. In 2 studies [17, 18], the length of the erector spinae, internal and external oblique was analyzed and although no significant differences were found with regard to the use of brace, the kind of brace and the curvature were significant $[17,18]$. In another study, the researchers also concluded that multifidus muscle was

Table 1. The anthropometric characteristics of the study subjects.

\begin{tabular}{|c|c|c|c|c|c|c|c|c|c|c|}
\hline & Number & $\begin{array}{l}\text { Height } \\
(\mathrm{cm})\end{array}$ & $\begin{array}{c}\text { Weight } \\
\text { (kg) }\end{array}$ & Age & $\begin{array}{l}\text { Leg length } \\
(\mathrm{mm})\end{array}$ & Pelvis width & $\begin{array}{l}\text { Foot length } \\
(\mathrm{mm})\end{array}$ & $\begin{array}{l}\text { Curva- } \\
\text { ture kind }\end{array}$ & $\begin{array}{c}\text { Angel } \\
\text { (degree) }\end{array}$ & $\begin{array}{c}\text { The head } \\
\text { of the } \\
\text { curve }\end{array}$ \\
\hline \multirow{5}{*}{$\begin{array}{c}\text { The } \\
\text { Patients }\end{array}$} & 1 & 162 & 36 & 14 & 940 & 218 & 246 & \multirow{2}{*}{ A } & 25 & 25 \\
\hline & 2 & 142 & 37 & 12.3 & 780 & 231 & 222 & & 37 & 37 \\
\hline & 3 & 154 & 43.7 & 13.5 & 820 & 265 & 223 & \multirow[t]{2}{*}{$\begin{array}{c}\text { C- } \\
\text { shaped }\end{array}$} & 30 & 30 \\
\hline & 4 & 155 & 44 & 12.6 & 800 & 240 & 236 & & 32 & 32 \\
\hline & 5 & 156 & 27 & 11 & 820 & 241 & 223 & curvature & 35 & 35 \\
\hline \multicolumn{2}{|c|}{ Mean $\pm S D$} & $153.8 \pm 7.39$ & $37.54 \pm 6.95$ & $12.68 \pm 1.16$ & $832 \pm 62.61$ & $239 \pm 17.22$ & 23010.65 & - & - & - \\
\hline
\end{tabular}

* The distance is between the greater trochanter of the femur to Earth.

PHYSICAL TREA TMENTS

** The distance is between the anterior superior iliac spine on the right and left.

Table 2. The correlated t-test results of spatiotemporal variables with and without brace in patients.

\begin{tabular}{cccc}
\hline Variable & $\begin{array}{c}\text { Without brace } \\
\text { Mean } \pm \text { SD }\end{array}$ & $\begin{array}{c}\text { With brace } \\
\text { Mean } \pm \text { SD }\end{array}$ & P-value \\
\hline Cadence $($ step $/ \mathrm{min})$ & $106.7 \pm 8.07$ & $110.2 \pm 4.97$ & 0.19 \\
Speed $(\mathrm{m} / \mathrm{s})$ & $1.12 \pm 0.12$ & $1.16 \pm 0.09$ & 0.08 \\
Step length $(\mathrm{m})$ & $1.26 \pm 0.026$ & $1.27 \pm 0.05$ & 0.74 \\
\hline
\end{tabular}


Table 3. The results of the correlated kinematic T-values in the hip, knee, pelvis, and spinal cord with and without brace.

\begin{tabular}{|c|c|c|c|c|}
\hline \multicolumn{2}{|c|}{ Variable (degree) } & \multirow{2}{*}{$\begin{array}{c}\begin{array}{c}\text { Without brace } \\
\text { Mean } \pm S D\end{array} \\
0.45\end{array}$} & \multirow{2}{*}{$\begin{array}{c}\text { With brace } \\
\text { Mean } \pm \text { SD }\end{array}$} & \multirow{2}{*}{$\begin{array}{c}\text { P-value } \\
0.23\end{array}$} \\
\hline 0.45 & 0.45 & & & \\
\hline 0.7 & 0.7 & 0.7 & 0.7 & $0.006^{* *}$ \\
\hline 0.05 & 0.05 & 0.05 & 0.05 & 0.80 \\
\hline 0.047 & 0.047 & 0.047 & 0.047 & 0.31 \\
\hline 0.05 & 0.05 & 0.05 & 0.05 & 0.97 \\
\hline 0.2 & 0.2 & 0.2 & 0.2 & 0.35 \\
\hline 0.08 & 0.08 & 0.08 & 0.08 & 0.39 \\
\hline 0.08 & 0.08 & 0.08 & 0.08 & 0.37 \\
\hline 0.99 & 0.99 & 0.99 & 0.99 & $0.02^{*}$ \\
\hline \multirow[t]{2}{*}{0.24} & 0.24 & 0.24 & 0.24 & 0.10 \\
\hline & 0.12 & 0.12 & 0.12 & 0.42 \\
\hline
\end{tabular}

$* \mathrm{P}<0.05, * * \mathrm{P}<0.01$

PHYSICAL TREA † MENTS

Table 4. The results of the correlated t-test of the normalized changes in the length of the fiber muscle to the resting length in 2 groups with and without brace.

\begin{tabular}{|c|c|c|c|c|}
\hline \multicolumn{2}{|c|}{ Muscle (mm) } & $\begin{array}{c}\text { Without brace } \\
\text { Mean } \pm S D\end{array}$ & $\begin{array}{l}\text { With brace } \\
\text { Mean } \pm S D\end{array}$ & P-value \\
\hline \multirow{3}{*}{ Erector spinae } & Right & $75.00 \pm 5.00$ & $73.00 \pm 6.00$ & 0.57 \\
\hline & & & & \\
\hline & Left & $76.00 \pm 4.30$ & $72.50 \pm 11.00$ & 0.82 \\
\hline \multirow{2}{*}{ Internal oblique } & Right & $130.00 \pm 8.20$ & $130.00 \pm 3.40$ & 0.05 \\
\hline & Left & $120.00 \pm 77.00$ & $120.00 \pm 29.00$ & 0.82 \\
\hline \multirow{3}{*}{ External oblique } & Right & $160.00 \pm 8.60$ & $160.00 \pm 9.00$ & 0.36 \\
\hline & & & & \\
\hline & Left & $158.00 \pm 8.70$ & $140.40 \pm 7.00$ & 0.07 \\
\hline
\end{tabular}

shorter in the convex curve [17]. In this study due to the lack of the software, it was not possible to measure the multifidus muscle.

One of the fundamental methods in the treatment of the scoliosis is using brace and Maruyama et al. in their latest research referred to it as an evidenced-based therapy. Scoliosis leads to an adverse deviation in the spine. This adverse deviation, especially in the immature people ends with the symptoms such as backache, spine mobility decrease, low lungs' function and or psychological symptoms like poor self-image that can lead to low selfesteem $[23,24]$. Scoliosis, however, is a lateral curvature in the spine that affects the consistency of standing and walking kinematics $[25,26]$.

The results showed that although the patients' movement range during walking with brace in most of their muscles and most walking planes were lower than those in walking without brace, these decreases were not significant. The motion range of the sagittal trunk during walking with brace was significantly 3.2 degrees lower than the walking without brace. These limitations in the motion rang of the trunk in the sagittal plane during walking with brace can be related to the brace function in the motion range. The brace used in the present study was Boston brace. The area covered by the brace in the 
front started from xiphoid appendage to the pubis and fitted the back and lateral curve and changes for each pattern with scoliosis curvature. What is clear is that the posterior brace interfering which is from xiphoid appendage to the pubis muscle limits the trunk flexion and extension. This imposed limitation by the brace, with the decrease in the trunk movement range in sagittal plane, is present in the patients. Pelvis motion in the frontal plane had a significant increase during walking with brace. This increase in the motion range in of the pelvis frontal range probably is a compensatory movement to decrease in the spine motion range. It is necessary for making a movement range for walking.

The researchers did not observe any significant difference in the convexity and concavity of the patients with scoliosis $[17,27]$ and stated that the decrease in the range for pelvis, trunk, and shoulder movements were very low and from 1.6 to 4.6 .

Researchers also reported that in investigating the motion range of patients with scoliosis and arthritis during walking compared to the patients without arthritis, the trunk motion range of these patients significantly decreased in sagittal, frontal, and horizontal planes [13, 29-31].

Although the results of the present study showed that the trunk motion range decreased in the sagittal, frontal, and horizontal planes, the observed significant difference was just correspondent with the researchers' results in the trunk sagittal motion range.

With regard to the changes in the muscle fibers, however, few studies and cases have been reported [17, 18]. Given the importance of the issue, more research on the changes in the length of the muscle fiber in scoliosis is needed. The results of the present study on the length of the trunk muscle are distinctive. The results showed that using the brace decreased the length of some muscles in patients with scoliosis during walking. However, the decrease in the length of the fiber was only seen in the right and left erector spine and left external oblique, no changes were observed in the length of the other muscles. Also, the decrease in the length of the mentioned muscles was not significant, this little amount of change in the length may probably been resulted from the unskillful use of brace.

The results of the motion range showed that the trunk motion range in sagittal plane decreased indicating a limitation in the trunk motion by brace. Using brace and limitation in the trunk motion during walking changes the length of the trunk muscles, especially the external oblique and erector spine. Some studies reported an asymmetry in the electromyographic activity of these muscles as the main cause of scoliosis. Other studies (conducted with the control group) indicated the simultaneous and longer contraction increase in the muscles of the related convexity and concavity that might be the reason of limited trunk and pelvis motion of the patients compared to the normal group [28]. The results of the other studies also indicated no significant difference in the length of the erector spinae, internal and external oblique muscles in both right and left sides of the patients with scoliosis by using orthotics [17].

The results of the present study showed that the length of the erector spinae and external oblique during wearing brace decreased. Therefore, it is recommended that physiotherapists and rehabilitation specialists consider the increase in the flexibility of the erector spine and external oblique muscles. Because using brace limits the movement and changes in the length of these muscles, the activities in these muscles, probably, will be affected by the brace during walking. In the long run, the lower activities of these muscles will eventually lead to the muscle weakness. Therefore, more research is needed to examine and investigate the amount of forces produced by these muscles during walking with and without brace.

Because of the software limitations, it was not possible to examine all the trunk muscles, which are probably influential in the scoliosis. Another limitation of the study was the small size of the sample. Therefore, due to the few studies on this field of and its novelty, it is recommended that this research be conducted on a larger group of the patients with scoliosis.

Wearing brace can decrease the range of the trunk motion, especially in the sagittal plane which leads to the changes in the length of the erector spinae muscles and external oblique. Therefore, it is recommended that rehabilitation staff consider the flexibility and strengthening these muscles. More research is needed to investigate the weakness of these muscles after a long-term use of the brace.

\section{Acknowledgements}

The authors are grateful to the patients and their parents for participating in this study.

\section{Conflict of Interests}

There is no conflict of interest. 


\section{Refrences}

[1] Rogala EJ, Drummond DS, Gurr JE. Scoliosis: incidence and natural history, a prospective epidemiological study. Journal of Bone \& Joint Surgery. 1978; 60(2):173-76.

[2] Nachemson AL, Sahlstrand T. Etiologic factors in adolescent idiopathic scoliosis. Spine. 1977; 2(3):176-84.

[3] Burwell R, Cole A, Cook T, Grivas T, Kiel A, Moulton A, et al. Pathogenesis of idiopathic scoliosis: the Nottingham concept. Acta Orthopaedica Belgica. 1991; 58:33-58.

[4] de Mauroy CJ, Lecante C, Barral F. “Brace technology” thematic series: the lyon approach to the conservative treatment of scoliosis. Scoliosis. 2011; 6:4. doi: 10.1186/1748-7161-6-4

[5] Grivas TB, Bountis A, Vrasami I, Bardakos NV. Brace technology thematic series: the dynamic derotation brace. Scoliosis. 2010; 5:20. doi: 10.1186/1748-7161-5-20

[6] Moe JH. Indications for Milwaukee brace non-operative treatment in idiopathic scoliosis. Clinical Orthopaedics and Related Research. 1973; 93(2):38-43.

[7] van Loon PJ, Roukens M, Kuit JD, Thunnissen FB. A new brace treatment similar for adolescent scoliosis and kyphosis based on restoration of thoracolumbar lordosis: Radiological and subjective clinical results after at least one year of treatment. Scoliosis. 2012; 7:19. doi: 10.1186/1748-7161-7-19

[8] Weiss HR, Negrini S, Rigo M, Kotwicki T, Hawes MC, Grivas $\mathrm{TB}$, et al. Indications for conservative management of scoliosis (SOSORT guidelines). Studies in Health Technology and Informatics. 2007; 135:164-70.

[9] Blount WP. Non-operative treatment of scoliosis with the Milwaukee brace. Manitoba Medical Review. 1965; 45(8):478-80.

[10] Aulisa AG, Mastantuoni G, Laineri M, Falciglia F, Giordano M, Marzetti E, et al. Brace technology thematic series: the progressive action short brace (PASB). Scoliosis. 2012; 7:6. doi: 10.1186/1748-7161-7-6

[11] Aulisa L, Lupparelli S, Pola E, Aulisa A, Mastantuoni G, Pitta L. Biomechanics of the conservative treatment in idiopathic scoliotic curves in surgical "grey-area". Studies in Health Technology and Informatics. 2001; 91:412-18.

[12] Wong MS, Cheng JC, Lam TP, Ng BK, Sin SW, Lee-Shum $\mathrm{SL}$, et al. The effect of rigid versus flexible spinal orthosis on the clinical efficacy and acceptance of the patients with adolescent idiopathic scoliosis. Spine. 2008; 33(12):1360-365.

[13] Mahaudens P, Banse X, Detrembleur C. Effects of short-term brace wearing on the pendulum-like mechanism of walking in healthy subjects. Gait \& Posture. 2008; 28(4):703-07.

[14] Gaudreault N, Arsenault AB, Larivière C, DeSerres SJ, Rivard $\mathrm{CH}$. Assessment of the paraspinal muscles of subjects presenting an idiopathic scoliosis: an EMG pilot study. BMC Musculoskeletal Disorders. 2005; 6:4. doi: 10.1186/14712474-6-14

[15] Haderspeck K, Schultz A. Progression of idiopathic scoliosis: an analysis of muscle actions and body weight influences. Spine. 1981; 6(5):447-55.

[16] Wynarsky GT, Schultz AB. Trunk muscle activities in braced scoliosis patients. Spine. 1989; 14(12):1283-286.
[17] Kaviani Brojeni M, Karimi MT, Ebrahimi A. The effects of Milwaukee orthosis on gait parameters in a Scoliotic subject. Journal of Research in Rehabilitation Sciences. 2013:1403-412.

[18] Karimi M, Kaviani Brojeni M. Scoliosis curve analysis with Milwaukee orthosis based on OpenSim modeling. Journal of Craniovertebral Junction \& Spine. 2015; 6(3):125-29. doi: 10.4103/0974-8237.161594

[19] Kadaba M, Ramakrishnan H, Wootten M, Gainey J, Gorton G, Cochran G. Repeatability of kinematic, kinetic, andelectromyographic data in normal adult gait. Journal of Orthopaedic Research. 1989; 7(6):849-60.

[20] Delp SL, Anderson FC, Arnold AS, Loan P, Habib A, John $\mathrm{CT}$, et al. OpenSim: open-source software to create and analyze dynamic simulations of movement. IEEE Transactions on Biomedical Engineering. 2007; 54(11):1940-950

[21] Kennelly KP, Stokes MJ. Pattern of asymmetry of paraspinal muscle size in adolescent idiopathic scoliosis examined by real-time ultrasound imaging: a preliminary study. Spine. 1993; 18(7):913-17.

[22] Maruyama T. Bracing adolescent idiopathic scoliosis: a systematic review of the literature of effective conservative treatment looking for end results 5 years after weaning. Disability and Rehabilitation. 2008; 30(10):786-91.

[23] Collis DK, Ponseti IV. Long-term follow-up of patients with idiopathic scoliosis not treated surgically. Journal of Bone \& Joint Surgery. 1969; 51(3):425-45.

[24] Payne WK, Ogilvie JW, Resnick MD, Kane RL, Transfeldt EE, Blum RW. Does scoliosis have a psychological impact and does gender make a difference? Spine. 1997; 22(12):1380-384.

[25] Arnold H. Etiology and pathogenesis of spinal abnormalities in the growing period: juvenile kyphosis and scoliosis. Monatsschrift fur Kinderheilkunde. 1957; 105(2):61-65.

[26] Chen PQ, Wang JL, Tsuang YH, Liao TL, Huang PI, Hang YS. The postural stability control and gait pattern of idiopathic scoliosis adolescents. Clinical Biomechanics. 1998; 13(1):52-58.

[27] Mahaudens P, Banse X, Mousny M, Detrembleur C. Gait in adolescent idiopathic scoliosis: kinematics, electromyographic and energy cost analysis. Studies in Health Technology and Informatics. 2011; 158:101-06.

[28] Mahaudens P, Banse X, Mousny M, Detrembleur C. Gait in adolescent idiopathic scoliosis: kinematics and electromyographic analysis. European Spine Journal. 2009; 18(4):512-21.

[29] Kramers-de Quervain IA, Müller R, Stacoff A, Grob D, Stüssi E. Gait analysis in patients with idiopathic scoliosis. European Spine Journal. 2004; 13(5):449-56.

[30] Wong M, Cheng C, Ng B, Lam T, Sin S, Lee-Shum L, et al. The effect of rigid versus flexible spinal orthosis on the gait pattern of patients with adolescent idiopathic scoliosis. Gait \& Posture. 2008; 27:189-95. doi: 10.1016/j.gaitpost.2007.03.007

[31] Karimi MT, Kaviani Brojeni M, Etemadifar MR. Gait analysis in adolescent idiopathic scoliosis walking with Boston brace. Scoliosis. 2014; 9(1):24. doi: 10.1186/1748-7161-9-S1$\mathrm{O} 24$ 
